African Journal of Biomedical Research, Vol. 11 (2008); 155 - 159

Full-text available at http://www.ajbrui.com http://www.bioline.br/md http://www.ajol.com

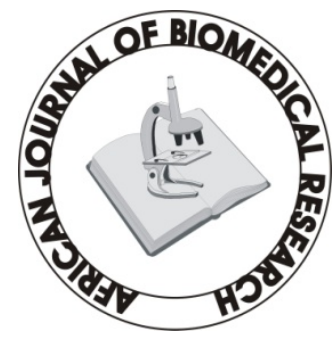

Received:

May 2007

Accepted (Revised):

March 2008

Published

May 2008
Full Length Research Article

\section{Hepatitis B Virus (HBV) Infection among Pregnant Women in Makurdi, Nigeria.}

\author{
${ }^{1}$ Mbaawuaga E. M, ${ }^{2}$ Enenebeaku M.N.O, ${ }^{3}$ Okopi J. A, J.G Damen ${ }^{4}$. \\ ${ }^{1}$ Department of Biological Sciences, Benue State University, Makurdi, Nigeria \\ ${ }^{2}$ Department of Medical Microbiology, University of Jos, Jos, Nigeria. \\ ${ }^{3}$ AIDS Prevention Initiative Nigeria (APIN), Jos University Teaching \\ Hospital, Jos. \\ ${ }^{4}$ Medical Microbiology Department, Jos University Teaching Hospital \\ (JUTH) Jos, Nigeria.
}

\section{ABSTRACT}

The prevalence of Hepatitis B Virus (HBV) carrier and infectivity status among three hundred (300) pregnant women in Makurdi were determined through random anonymous testing of volunteers attending antenatal clinics of different Hospitals within the metropolis. HBV carriage status was determined by the presence of Hepatitis B surface antigen (HBsAg). Repeated reactive samples were confirmed by Enzyme linked immunosorbent assay (ELISA) kit (Bio Rad, France). Maternal HBV infectivity status was determined by testing all HBsAg positive samples for the presence of hepatitis B e antigen (HBeAg). Overall, 33 (11\%) pregnant women were identified as carriers of HBV and 10 of the 33 (30.3\%) pregnant women identified as HBV carriers tested positive for HBeAg. Hence, $3.3 \%$ of the entire study population was found to have high viral replication as well as high risk of transmitting HBV to their neonates. The frequency of HBV carriers did not vary with age, however it varies significantly with the anaemic status of the subjects $(\mathrm{P}<0.05)$. This study demonstrates the endemicity of HBV infection in Makurdi and high infectivity rates, suggest that HBV is likely to be acquired by both vertical and horizontal means of transmission. Free screening and immunization of all pregnant women and infants should be incorporated in the antenatal and post natal programmes in hospitals for the eradication of $\mathrm{HBV}$ infection among pregnant women.

Key words: Hepatitis B Virus - Hepatitis B surface antigen - Hepatitis Be antigen Pregnant Women - Prevalence

(Afr. J. Biomed. Res. 11: 155- 159)

* Address for Corresponding author: E-mail: msughawuaga@yahoo.com

Abstracted by:

African Index Medicus (WHO), CAB Abstracts, Index Copernicus, Global Health Abstracts, Asian Science Index, Index Veterinarius, Bioline International , African Journals online 


\section{INTRODUCTION}

Hepatitis $\mathrm{B}$, one of the major and common infectious diseases of the liver world wide is caused by a small enveloped DNA virus, the hepatitis B virus (HBV). The virus was first discovered as "Australia antigen", later named hepatitis B surface antigen (HBsAg), in patient blood. Hepatitis B e antigen (HBeAg) was identified several years later as a marker for patients at high risk for transmission of the disease (Tong et al, 2005).

It is estimated that more than two billion people have been infected by HBV world wide and 350 million people have chronic infection (Uneke et al, 2005). When a pregnant woman is infected with $\mathrm{HBV}$, there is a chance she may infect her foetus. It has been reported that $10-20 \%$ of women seropositive for HBsAg transmit the virus to their neonates, but in women who are seropositive for both HBsAg and HBeAg, vertical transmission is approximately 90\% (Vranckx et al, 1999). Chronic HBV infection have been defined as carriage of HBsAg for at least 6 months and the highest risk (80 - 90\%) of chronic infection have been found among infected neonates born to HBeAg positive carrier mothers followed (30\%) by children infected before 6 years of age (Hyams, 1995).

Nigeria is classified among the group of countries endemic for HBV infection. Currently about 18 million Nigerians are infected (Sirisena et al, 2002, Jombo et al, 2005). Many of these people may not be aware of the infection and hence fail to seek appropriate medical attention therefore progressing to chronic liver disease, cirrhosis and hepatocellular carcinoma. Similarly when pregnant women are involved they constitute a serious health risk not only to their unborn child but also the society at large.

Although, studies have been carried up on $\mathrm{HBV}$ in other parts of the country, information is very scarce on the prevalence of $\mathrm{HBV}$ among pregnant women in Benue State. As a result guidelines and other adequate information on the prevention and control strategies are lacking. The objectives of this study therefore are to determine the prevalence of hepatitis $\mathrm{B}$ virus carrier and infectivity status of carrier pregnant women in Makurdi and to provide information on its prevention and control strategies.

\section{MATERIALS AND METHODS}

\section{Study Area}

The study was conducted in Makurdi metropolis which is located in an area covering about 16 square kilometer, in North-Central Nigeria. Its average annual rainfall is $1200 \mathrm{~mm}$ and the average annual maximum temperature is $33.4^{\circ} \mathrm{C}$. Makurdi have two Universities and two other post secondary institutions and has been endowed with agricultural viability which attract people from many other parts of the country. Consequently, the area is reported to have the highest prevalence of sexually transmitted diseases (Federal Ministry of Health, 2003).

\section{Selection of Subjects.}

All pregnant women attending antenatal clinics in different hospitals in Makurdi metropolis were eligible for the study. Participation was voluntary and each subject involved in the study gave a written consent. The recruitment was by a simple random sampling method from January to April 2005. Three hundred (300) subjects aged 10 to 49 years were involved in the study. The ethical approval was obtained from the ethical committee of Benue State Ministry of Health and Human Services, Makurdi.

\section{Variables.}

The following information were requested from the subjects in a structured questionnaire; age, occupation, marital status, sex during menstrual period, previous use of contraceptive devices, herbal medicine consumption, smoking and alcoholic consumption. Subjects were asked whether they had suffer from arthritis or not and their blood group as well as Packed Cell Volume (PCV) were checked.

\section{Collection of sample/Analysis}

Five milliliter $(5 \mathrm{ml})$ of blood was obtained by venopuncture. One milliliter $(1 \mathrm{ml})$ of the freshly 
collected blood was introduced into an EDTA bottle for PCV and ABO blood grouping. The remaining $(4 \mathrm{ml})$ was introduced into a clean test tube, allowed to clot naturally and separated by centrifugation at 1,500 revolutions per minute (rpm). Part of the sera collected was tested for hepatitis B surface antigen (HBsAg) using latex rapid agglutination slide test kits (Cal - Tech Diagnostic, Inc. USA.) in the laboratories of the hospitals where the samples were collected. Reactive samples were stored at $-20^{\circ} \mathrm{C}$ and further confirmed for HBsAg using commercially available enzyme linked immunosorbent assay kit (ELISA) (Bio Rad, France) in immunology laboratory of Jos Teaching Hospital (JUTH). HBsAg positive samples were also tested for HBeAg using ELISA kit (ORGENICS, Israel).

\section{Statistical Analysis}

Results obtained were subjected to statistical analysis using statistical package for social sciences (SPSS) version 11.

Comparism of proportion was done using chisquare test while $\mathrm{P}$ values less than 0.05 were considered significant.

\section{RESULTS}

Of the 300 subjects recruited into the study, 33 (11\%) pregnant women were seropositive for Hepatitis B surface antigen (HBsAg). The prevalence of HBsAg was highest among the teenagers $(10-19$ years). Ten of the 33 (30.3\%) pregnant women identified as HBV carriers (HBsAg+), tested positive for HBeAg. Hence, $3.3 \%$ of the entire study population was positive for HBeAg (Table 1).

Table1:

Age Seroprevalence of Hepatitis B Surface Antigen and Hepatitis B e Antigen among Pregnant Women in Makurdi, 2005

\begin{tabular}{|c|c|c|c|}
\hline Age group & Number tested & HBsAg positivity & HBeAg positivity \\
\hline $10-19$ & 20 & $4(20.0 \%)$ & $3(15.0 \%)$ \\
\hline $20-29$ & 185 & $18(9.7 \%)$ & 3 (1.6\%) \\
\hline $30-39$ & 89 & 11 912.4\%) & 4 (4.5\%) \\
\hline $40-49$ & 6 & $0(0 \%)$ & $0(0 \%)$ \\
\hline Total & 300 & $33(11.0 \%)$ & $10(3.3 \%)$ \\
\hline \multirow[t]{2}{*}{$\chi^{2=} 2.869$} & \multirow[t]{2}{*}{$\chi^{2}=10.710$} & $\mathrm{df}=3$ & \multirow[t]{2}{*}{$\mathrm{df}=3$} \\
\hline & & $>0.05$ & \\
\hline
\end{tabular}

Table 2:

Seroprevalence of Hepatitis B Surface Antigen in Relation to Associated Risk Factors among Pregnant Women in Makurdi, 2005.

\begin{tabular}{|l|l|l|l|l|}
\hline Risk Factors & & $\begin{array}{l}\text { Number } \\
\text { Tested }\end{array}$ & Positivity & $\chi^{2}, \mathrm{df}=1, \mathrm{P}$ value \\
\hline Blood transfusion & Yes & 35 & $4(11.4 \%)$ & $0.006,>0.05$ \\
& No & 264 & $29(11.0 \%)$ & \\
Contraceptive use & Yes & 89 & $13(14.6 \%)$ & $1.572,>0.05$ \\
& No & 208 & $20(9.6 \%)$ & \\
Herbal medicine use & Yes & 182 & $21(11.5 \%)$ & $0.235,>0.05$ \\
Anaemic status & No & 113 & $11(9.7 \%)$ & \\
& Anaemic & 41 & $9(22.0 \%)$ & $5.627,<0.05$ \\
Arthritis & Not anaemic & 228 & $21(9.2 \%)$ & \\
\multirow{5}{*}{ Set during menses } & Yes & 40 & $5(12.5 \%)$ & $0.095,>0.05$ \\
& No & 258 & $28(10.9 \%)$ & \\
Alcoholic consumption & Yes & 41 & $6(14.6 \%)$ & $0.641,>0.05$ \\
& No & 259 & $27(10.4 \%)$ & \\
& Yes & 95 & $8(8.4 \%)$ & $0.970>0.05$ \\
\hline
\end{tabular}


Table 3:

Age Distribution of HBsAg and HBeAg among Anaemic Pregnant Women in Makurdi, 2005.

\begin{tabular}{|l|l|l|l|}
\hline Age Group & Number Tested & Anaemic & HBsAg Positivity \\
\hline $10-19$ & 20 & $7(35.0 \%)$ & $2(28.6 \%)$ \\
$20-29$ & 185 & $29(15.7 \%)$ & $6(20.7 \%)$ \\
$30-39$ & 89 & $5(5.6 \%)$ & $1(20.0 \%)$ \\
$40-49$ & 6 & $0(0 \%)$ & $0(0 \%)$. \\
\hline Total & $\mathbf{3 0 0}$ & $\mathbf{4 1 ~ ( 1 3 . 7 \% )}$ & $\mathbf{9 ( 2 2 . 0 \% )}$ \\
\hline \multicolumn{2}{l}{} \\
\cline { 2 - 2 } & $\chi^{2}=16.898$ & $\chi^{2}=3.651$ \\
& $\mathrm{df}=3$ & $\mathrm{df}=2$ \\
& $\mathrm{P}<0.001$ & $\mathrm{P}>0.05$
\end{tabular}

Table 4:

Distribution of HBsAg and HBeAg among Pregnant Women that Previously used Contraceptive Device(s)

\begin{tabular}{|l|l|l|l|}
\hline Contraceptive device (s) & Number tested & HBsAg Positivity & HBeAg Positivity \\
\hline Injectable & 19 & $2(10.5 \%)$ & $0 \%$ \\
Loop & 1 & 0 & $0 \%$ \\
Oral pills & 52 & $9(17.3 \%)$ & $4(7.7 \%)$ \\
Pills/injectable & 12 & $1(9.1 \%)$ & $0 \%$ \\
Pills/loop & 2 & $1(50.0 \%)$ & $0 \%$ \\
\hline Total & $\mathbf{8 6}$ & $\mathbf{1 3 ( 1 5 . 1 9 \% )}$ & $\mathbf{4 ( 4 . 7 \% )}$ \\
\hline
\end{tabular}

The frequency of HBV carriers did not vary significantly with blood transfusion, previous use of contraceptive devices, and previous sex during menses, arthritis, herbal medicine consumption and alcoholic consumption. However, there was a significant frequency variation in the distribution of HBsAg between anaemic and non-anaemic subjects $\left(\chi^{2}=5.627, \mathrm{df}=1, \mathrm{P}<0.05\right)$ (Table 2). HBV carriers also decrease as anaemia decreases significantly ( $\chi^{2}=16.898, \mathrm{df}=\mathrm{P}<0.001$ ) with increasing age (Table 3$)$.

Blood group $\mathrm{A}$ and $\mathrm{AB}$ have higher frequencies of $\mathrm{HBV}$ carriers but statistically insignificant $\left(\chi^{2}=0\right.$. 937, $\left.\mathrm{df}=3, \mathrm{P}>0.05\right)$. Among all the contraceptive devices previously used by the subjects, only users of oral pills were positive for HBeAg. (Table 4)

\section{DISCUSSION}

The classification of high endemicity from HBV infection has been defined as HBsAg greater than $7 \%$ in an adult population (Uneke et al, 2005). The HBsAg seropositivity of $11 \%$ among pregnant women in Makurdi shows that Makurdi like other areas in Nigeria is endemic for HBV infection. This result is in conformity with an earlier report that sub-Saharan Africa has HBV carrier rate range of $9-20 \%$ (Kiire, 1996). The HBsAg prevalence of $11 \%$ is similar to the finding of Harry et al, (1994) who found $11.6 \%$ among pregnant women in Maiduguri, Borno State, Nigeria. The prevalence of $11 \%$ in comparism with $12.6 \%$ obtained by Jombo et al, (2005) in a study carried out in a rural community in Northcentral Nigeria, confirmed that, though the research was hospital and urban based, it has a high tendency of reporting accurate figures of the community. This is because the subjects were not patients but pregnant women attending their routine antenatal health care clinics.

HBeAg seroprevalence of $3.3 \%$ in the entire study population implies that one of every forty five subject or one of every three HBV carriers $(10 / 33$ or $30.3 \%)$ is at high risk of transmitting HBV to her neonate as well as higher chances of chronicity. This is alarming but tallies with the result of Olubuyide et al (1997), who found 34\% among HBsAg positive doctors and dentist at University Teaching Hospital Ibadan. However, it is very high when compared with $0.8 \%$ found by Madzime et al (1999), in Zimbabwe as well as 6.64\% and 1.39\% obtained by Harry et al (1994), among blood donor and pregnant women in Maiduguri respectively. Hence the issue of vertical 
transmission in sub-Saharan Africa cannot be ignored.

High frequency of HBV carriers among teenagers $(10-19)$ and $30-39$ age groups and the corresponding high HBeAg prevalence among the same age groups further shows the severity of the infection in the community. This distribution as shown in Table 2 and 3 could be due to anaemia which significantly decreases with increasing age. It can also be attributed to the effect of oral pills (Table 4) towards higher expression of HBeAg (Table 1) among the teenagers and 30 -39 age group. Oral pills are steroid hormone prepared in tablet form and have slower but longer action in the body stimulating the immune system for a longer period of time. They have been reported to immunosuppress (blind) lymphocytes by reducing the reactivity of T-lymphocytes and reduce immunoglobulin secretion (Masset et al, 1980; Presl, 1981). Hence, anemia, effect of oral pills as well as unanalyzed factors such as malaria and HIV may have contributed immensely to the endemicity of $\mathrm{HBV}$ infection among pregnant women in Makurdi and the community at large.

In conclusion, this study has provided information on the prevalence of HBV infection in Makurdi, Nigeria. Teenage pregnant women should be seriously monitored to avoid anemia. Free screening and immunization of all pregnant women and their infants should be incorporated in the antenatal and postnatal programmes in hospital to prevent postnatal infection of the infants by their infected mothers. The use of other HBV infection serological markers such as anti HBs, anti HBc and anti HBe as well as malaria, HIV coinfections is advocated for future studies.

\section{ACKNOWLEDGEMENT}

Profound gratitude goes to Benue State University Board of Research for the financial assistance towards this work. Thanks also go to the management and staff of Family Support Clinic Makurdi; Bishop Murray Hospital Makurdi, City Hospital Makurdi for their immense assistance. Similarly we acknowledge the voluntary assistance of the staff of the Immunology Laboratory of JUTH in analyzing the sera for confirmation.

\section{REFERENCES}

Federal Ministry of Health Niger, (2003): National HIV/AIDS and Reproductive Health Survey, Abuja, 209

Harry, T.O, Bajani, M. D, Moses, A.E (1994): Hepatitis B Virus infection among blood donors and pregnant women in Maiduguri, Nigeria. East Afr Med J. 71 (9): 596-597

Hyams, K. C (1995): Risks of Chronicity following acute hepatitis B Virus infection: a review. Clin Infect Dis 20 (4); $992-1000$.

Jombo G.T.A, Egah, D.Z, Banwat E.B (2005): Hepatitis B Virus infection in a rural Settlement of Northern, Nigeria. Niger J Med 14 (4): 425 - 428.

Kiire C.F (1996): The epidemiology and Prophylaxis of hepatitis B in Sub-Saharan Africa: a review from tropical and subtropical Africa. Gut 38 (2): 5-12

Madzime S, Adem M, Mohammed K., Woelk G.B, Mudzamiri S, Williams M. A (1999): Hepatitis B virus infection among pregnant women delivering at Harare Maternity Hospital, Harare, Zimbabwe, 1996 to 1997. Central Afr. J Med 45 (8): $195-198$.

Masset B, Cuevas M, Gerard J.P (1980): Analysis of Serum-mediated Immunosuppression in normal pregnancy, abortion and contraception. Allergol Immunopathol (Madr) 8 (5): 569 - 578.

Olubuyide I. O, Ola S .0., Aliyu Dosumu O.O., Arotiba J.T., Olaleye O.A, Odaibo GW, Odemuyiwa S.O, Olawayi F (1997): Hepatitis Band C in doctors and dentist in Nigeria. Q J Med 90: 417 - 422.

Presl J (1981). Risks and perspectives of steroid contraceptives. Cesk Synekol 46 (1): 50-58.

Sirisena N. D, Njoku M.O., Idoko J.A., Isamade E, Barau C, Jelpe D., Zamani A, Otowo S (2002): Carriage rate of hepatitis B Surface antigen (HBsAg) in an urban community in Jos, Plateau State, Nigeria. Niger postgrad med J. 9 (1): 7-10.

Tong S, Kim K.H, Chante C, Wands J, Li J (2005): Hepatitis B Virus the antigen variants. Int J med Sci. 2:2-7.

Uneke C.J, Ogbu O, Inyama. P.U., Anyanwie g.I., Njoku M.O, Idoko J.H (2005) Prevalence of hepatitis $B$ surface antigen among blood donors and Human immunodeficiency Virus - infected patients in Jos, Nigeria. Mem Inst Oswaldo Cruz, Rio de Janeiro, 100 (1): $13-16$.

Vranckx R., Alisjahbana A, meheus A (1999). Hepatitis B. Virus Vaccination and antenatal transmission of HBV markers to neonates J. Viral Hepatitis 6 (2): 135 - 39. 
African Journal of Biomedical Research, Vol. 11 (2008); 155 - 159

ISSN 1119 - 5096 @ Ibadan Biomedical Communications Group



Abstracted by:

African Index Medicus (WHO), CAB Abstracts, Index Copernicus, Global Health Abstracts, Asian Science Index, Index Veterinarius, Bioline International , African Journals online 